\title{
Colonialidade do saber e conflitos de memórias no espaço público ${ }^{\star}$
}

\author{
Heliana Castro Alves ${ }^{(D)} \star \star$ \\ Universidade Federal do Triangulo Mineiro, Uberaba, MG, Brasil
}

\begin{abstract}
Resumo
A colonialidade do poder e do saber pode transcender a relação da Europa com os países colonizados, passando a se constituir como um padrão de relações reproduzido em diversos sistemas políticos. O eurocentrismo é uma perspectiva cognitiva-epistêmica não exclusiva dos europeus e nem do período colonial, pertencendo também aos que tenham sido educados pela sua hegemonia. Este relato de pesquisa tem por objetivo abordar a concepção e organização de um Memorial em uma comunidade quilombola, observando-se o processo de construção da memória coletiva em torno de um mito fundacional de origem. Na metodologia seguiu-se a abordagem qualitativa utilizando o método da história oral. Os dados foram analisados por meio da análise de conteúdo temática valendo-se do software Atlas Ti na codificação, categorização e monitoração da produção de sentidos. Observa-se que durante a construção do Memorial determinados grupos sociais dominantes utilizam o poder simbólico, social e político para fazer prevalecer sua representação de passado numa perspectiva epistemológica eurocêntrica, evitando a polissemia de vozes. $O$ guiamento do Memorial provoca, porém, um conflito de memórias a partir de relatos testemunhais que subvertem a temporalidade histórica da escravidão, imputando novas formas identitárias ao processo de construção da memória.
\end{abstract}

Palavras-chave: memória coletiva; colonialidade do saber; colonialidade do poder; comunidades quilombolas.

\section{Coloniality of knowledge and conflict of memories in the public space}

\begin{abstract}
The coloniality of power and knowledge can transcend the relationship of Europe with the colonized countries, becoming a pattern of relations reproduced in various political systems. Eurocentrism is a non-exclusive cognitive-epistemic perspective of Europeans and neither of the colonial period, also belonging to those who have been educated by their hegemony. This research report aims to approach the conception and organization of a memorial in a quilombola community observing the process of construction of the collective memory around a founding myth of origin. In the methodology followed the qualitative approach using the oral history method. The data were analyzed through the thematic content analysis using Atlas Ti software in the coding, categorization and monitoring of the production of meanings. It is observed that during the construction of Memorial certain dominant social groups use the symbolic, social and political power to make their representation of the past prevail in a Eurocentric epistemological perspective, avoiding the polysemy of voices. The Memorial guide, however, provokes a conflict of memories, based on witness accounts that subvert the historical temporality of slavery, imputing new identity forms to the process of memory construction.
\end{abstract}

Keywords: collective memory; coloniality of knowledge; coloniality of power; quilombola communities.

\section{Introdução}

Ao desenvolver a noção de colonialidade do saber, Quijano (2000) se refere ao poder epistêmico da Europa que a partir do sistema-mundo moderno expressa a centralidade da produção, legitimação e difusão de conhecimento. Considerando que a colonialidade do poder/ saber constitui um fenômeno que pode transcender a relação da Europa com os países colonizados, embora constitua sua origem histórica, é possível observar os processos de produção de conhecimento como expressão da colonialidade operando em níveis locais, ao longo das gerações, por meio da veiculação da memória genealógica da antiga elite colonial. Compreendendo que a colonialidade do poder e do saber é mantida por meio de uma memória socialmente construída e compactada pelo imaginário colonial enquanto perspectiva cognitiva, observa-se a possibilidade de relacionarmos os estudos da memória e os estudos pós-coloniais na área da psicossociologia.

A psicologia, isoladamente, enquanto disciplina focada nos fenômenos intrapsíquicos, não possibilita um alcance conceitual que dê conta de um objeto, como a

^Financiamento: Capes Cofecube e Capes Pro-doutoral.

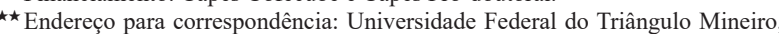
Instituto de Ciências da Saúde. Rua Frei Paulino, 30. Abadia, Uberaba, MG Brasil. CEP: 38025180.E-mail: helianasolar@gmail.com

Os dados completos da autora encontram-se ao final do artigo. memória, que fundamentalmente transcende os parâmetros da noção de um sujeito centrado, exigindo uma perspectiva interdisciplinar e multifocal. Sá (2007), ao traçar alguns parâmetros para a consolidação da memória no campo da psicossociologia, elenca alguns princípios que acabam por nortear um melhor entendimento desta aplicação neste campo. Um dos princípios está relacionado ao caráter construtivo da memória social: a memória não é uma reprodução pura das experiências passadas e sim uma construção em função da realidade presente (HALBWACHS, 2006). Desta forma, também a psicologia social passa a excluir uma perspectiva exclusivamente psicologista em que as experiências e recordações se apresentam intactas na memória, como se fosse um fenômeno puro (SÁ, 2007). Especificamente, pensar no caráter construtivo da memória social a partir do tempo presente constitui um objeto importante se refletirmos sobre o processo político-social que envolveu as comunidades quilombolas, uma vez que a possibilidade de autorreconhecimento destas comunidades no terreno político ofereceu uma porta para novos processos identitários.

O fenômeno da manutenção da colonialidade do poder/saber por meio das gerações expressando a predominância epistêmica da narrativa eurocêntrica pode ser observado no município de Quissamã, no norte flumi- 
nense, onde se encontra a comunidade quilombola Machadinha. Os acontecimentos sociopolíticos, próprios da contemporaneidade, impactam o processo de construção da memória coletiva da comunidade. Assim, o artigo trata sobre a concepção e organização de um Memorial nesta comunidade, observando-se a dinâmica das relações de poder tecida entre a administração municipal local e a comunidade no processo de construção da identidade e da memória coletiva.

\section{Metodologia}

Este artigo constitui um relato de pesquisa, realizado a partir do recorte de um estudo de doutorado e tem por objetivo relatar a concepção e organização de um Memorial dentro de uma comunidade quilombola, observando-se o processo de construção da memória coletiva em torno de um mito fundacional de origem. Na metodologia seguiu-se a abordagem qualitativa utilizando na coleta de dados o método da história oral para realizar as entrevistas; observação direta do cotidiano da comunidade e suas ações socioculturais; e pesquisa documental. Os dados, conteúdo temático, foram analisados valendo-se do software Atlas Ti na codificação, categorização e monitoração da produção de sentidos.

\section{O mito fundacional de origem em Quissamã: centralidade da narrativa eurocêntrica}

O passado colonial se inscreve no próprio nome do município, que surge a partir da narrativa - e perspectiva epistêmica - dos colonizadores: a história do negro Kissama, encontrado entre os índios pelos sete capitães no período colonial. Esta importante peculiaridade de Quissamã deve ser observada ao analisarmos como se dá o processo de reconstituição do passado e construção da memória coletiva nos seus diversos âmbitos, dimensões e perspectivas: vemos surgir em Quissamã um mito fundacional de origem.

A história de Quissamã remonta aos meados do século 16, a partir da exploração da Capitania de São Tomé, também chamada de Campos dos Goitacazes. Desde o início, quando a capitania pertencia ainda ao português Pero de Góis no século 16, já havia ocorrido muitas tentativas frustradas de colonização da área em consideração à forte resistência indígena na região e os obstáculos da natureza local. Depois destas tentativas frustradas, a capitania foi devolvida à Coroa Portuguesa pelo sucessor, Gil de Góis (MARIANI, 1987). No século 17, sete capitães lusitanos, proprietários de engenhos de açúcar, receberam, em retribuição pela luta de expulsão de franceses travada no Rio de Janeiro, algumas sesmarias que iam do rio Iguaçu ao rio Macaé. Em 1632, eles saíram pela primeira vez para desbravar as terras. Durante a segunda expedição exploratória encontraram, no meio de um agrupamento de índios, um único e isolado negro. Ao ser questionado sobre sua origem, o negro disse: "Kissama”, referindo-se a um povoado na África, na região de Angola. Algum tempo depois, estes mesmos "desbravadores" lusitanos retornaram procurando por tal negro. No entanto, ele já havia fugido do local, certamente desconfiado. Este evento deu origem ao nome daquela região.
Esta formação discursiva produzida na perspectiva do sistema-mundo moderno, como sinalizaria Quijano (1992), foi detalhadamente registrada em extensos memoriais de viagem dos exploradores. A posicionalidade narrativa deste evento tem como contingência histórica o colonialismo, pertencendo a uma elite escravocrata o completo poder de enunciação - um viés epistemológico eurocêntrico. Isto sugere que as narrativas colonialistas, perfeitamente observáveis nestes memoriais, ao se transformarem em um mito fundacional de origem, preservam a centralidade do olhar colonizador e reproduzem uma visão de mundo eurocêntrica e dominadora no encontro com o seu Outro. Sublinha-se na perspectiva teórica de colonial, que a modernidade encenada pelo centralismo europeu só existe a partir da invenção da América: a colonialidade é uma condição da modernidade, estabelecendo-se um esquema mental que não apenas justifica, mas legitima a desigualdade entre as sociedades no sistema-mundo moderno (RESTREPO; ROJAS, 2010). A perspectiva epistêmica eurocêntrica se refletia nos diários dos próprios colonizadores, dando à elite açucareira local e seus descendentes, o poder de enunciação e registro dos fatos históricos.

Junto à forte demanda identitária gerada pelo processo de autonomia administrativa de Quissamã, os jornais locais, nesta época, passaram a construir e divulgar extensamente a narrativa da origem histórica do nome da cidade a partir dos memoriais dos desbravadores do tempo colonial, e por isso muitos moradores mais velhos da comunidade só vieram a conhecer o mito do negro Kissama depois de adultos. A busca identitária diante da demanda da emancipação político-administrativa de Quissamã também culmina na rememoração, por meio da imprensa local, das narrativas genealógicas da família Carneiro da Silva - antiga elite açucareira -, tendo como berço o período de auge da cana-de-açúcar e a construção do Engenho Central. Este fato é enaltecido de forma comemorativa sem que a memória da escravidão seja mencionada ao menos como pano de fundo das riquezas produzidas e ostentadas nesse período.

As matérias dos jornais instrumentalizam o processo de reconstrução da memória a partir das necessidades do presente: a euforia social pela emancipação da antiga Freguesia Nossa Senhora do Desterro de Quissamã em município corporifica a demanda pela identidade, ou ainda, a demanda da elite que pretende permanecer no poder. Como afirma Paul Ricoeur (2007), a fragilidade identitária traz demandas para a produção de memórias, sendo que - acrescentaria Foucault (2013) - todo discurso precisa ser analisado a partir da irrupção dos acontecimentos. O momento político da emancipação parece reativar a memória social, tendo como locus enunciativo a história da elite açucareira e sua linhagem genealógica através do tempo. A invisibilidade ou o "esquecimento" da escravidão nesta recordação evidencia a centralidade da memória genealógica da elite a partir das prerrogativas positivistas de progresso nacional. Observa-se, portanto, que as demandas pela construção de uma identidade durante o processo de municipalização de Quissa- 
mã geraram a evocação de uma memória oficializada que surge a partir da narrativa dos antigos colonizadores e se reinscreve no presente, instrumentalizando o processo de legitimação do poder instituído.

\section{Comunidade Quilombola Machadinha: processo de} construção identitária no interior das relações de poder

Em 2001, a prefeitura municipal desapropria o território que era da antiga usina de cana-de-açúcar e compra as terras da fazenda Machadinha. Em 2006, a comunidade se organiza e conquista a certificação palmares como comunidade quilombola compreendendo, ao todo, cinco fazendas e sítios. Após a aquisição da fazenda Machadinha, a prefeitura dá início ao processo da chamada "revitalização" deste local de memória a partir da criação do "Complexo Cultural da Fazenda Machadinha". Este complexo é constituído pelo conjunto arquitetônico preservado na fazenda desde a escravidão (antigas senzalas e ruínas da casa-grande) e por diferentes práticas culturais locais: o tambor/ jongo, o fado e a culinária. É importante observar que ocorre uma intensificação das atividades voltadas para o turismo no município aproveitando a memória do período colonial. As antigas senzalas foram reformadas, o jongo passou por um processo de reapropriação e foram criados outros aparatos dentro do território quilombola para o incentivo da atividade econômica do turismo cultural: a Casa de Artes e o Memorial Machadinha.

O processo de revitalização do espaço público e das festas populares na comunidade quilombola envolveu a produção da memória coletiva a partir das relações de poder estabelecidas com agentes culturais diretamente ligados à administração pública local que, não obstante, desde a municipalização de Quissamã, era ocupada pela descendência da antiga elite açucareira. De fato, a prefeitura passou a se interessar pelo potencial econômico do turismo, possibilitado pela onda memorialista em torno da escravidão no mundo todo e do processo de valorização das manifestações artístico-culturais e religiosas afro-brasileiras nas recentes políticas culturais. A comunidade quilombola passa a ser alvo do turismo global que materializa a cultura popular subalterna como objeto de consumo sob a égide do mercado neoliberal, impactando direta e indiretamente a produção da memória coletiva em torno da escravidão.

O jongo, que há muitos anos já não era mais dançado na comunidade, passa a ser resgatado e ressignificado pelo Poder Público tornando-o palatável aos turistas pela via da espetacularização. O processo de mediação, para Martín-Barbero (1997, p. 262), “é constituído pelos dispositivos através dos quais a hegemonia transforma por dentro o sentido do trabalho e da vida na comunidade". Essa mudança de sentidos provoca, para o autor, um esvaecimento da memória, tanto para o turista, quanto para a comunidade. Assim, convertem-se as culturas regionais, fazendo do turismo uma via de estereotipação de cerimônias e objetos (MARTÍN-BARBERO, 1997). O Memorial Machadinha, construído nessa época de intenso investimento público no turismo,torna-se um equipamento social voltado unicamente para este fim, somando, em sua prática cotidiana, a arquitetura, as festas e danças populares como o jongo. Este Memorial é entendido, portanto, enquanto "lugar de memória", conflito e negociação identitária, abordando o mito fundacional do negro Kissama, presente na memória de Quissamã e narrado pelos jongueiros da comunidade após o processo de "revitalização" da cultural local. Este espaço de produção, negociação e conflitos de memórias revela as relações de poder no interior do fato político quilombola, possibilitando uma discussão sobre a memória da escravidão na contemporaneidade e as lutas pós-coloniais travadas no atual quadro político a partir da memória coletiva.

\section{O Memorial Machadinha como lugar de conflito de memórias: uma perspectiva epistêmica contra- hegemônica surge no espaço público?}

Em 2008, a prefeitura realizou um grande projeto enviando pesquisadores e alguns representantes do Poder Público local para Angola. Tratava-se de uma missão de "busca das origens" que tinha por objetivo a procura de informações e contatos com pesquisadores e museus locais em Angola. O que motivou esse grande empreendimento cultural foi, justamente, a memória do negro Kissama, cuja imagem objetificada se torna um dos pilares icônicos das ações da prefeitura para a implementação de projetos culturais tendo por alvo a Comunidade Quilombola Machadinha. Observa-se nesta narrativa atemporal o esforço da construção do mito fundacional de origem, ligando Quissamã a Kissama. O retorno às "origens" africanas a partir de uma narrativa congelada no tempo parece constituir um "excesso de memória", em seu uso político-identitário que se projeta a partir de uma plena expressão pública desta memória (RICOEUR, 2007).

Este esforço de reconstituição do passado a partir da busca de um "elo perdido" sobrepõe a funcionalidade política e econômica da memória, enquanto estratégia instrumental, aos aspectos concretos da memória histórica. Após a viagem à África foi publicado um livro intitulado: Machadinha: origem, história e influências (SILVA, 2009), divulgado nas escolas e disponibilizado para turistas dentro do Memorial. A Comunidade Machadinha, portanto, é especialmente marcada por esta memória reiteradamente ilustrada pela imagem objetificada de um certo negro apelidado de Kissama pelos colonizadores no século 17: o mito fundador que surge a partir da narrativa dos colonizadores se transforma num recurso patrimonial e turístico. Da viagem à África, realizada pela prefeitura, foram trazidos muitos objetos tradicionais de Angola/ Luanda que passaram a fazer parte do Memorial Machadinha. Enquanto escolha estética na organização do Memorial, as fotos do povo de Angola foram misturadas às fotos do povo de Machadinha, apresentando como subtítulo: "Se colocarmos as fotos juntas, não sabemos quem é de Angola e quem é de Machadinha". A reivindicação da população de Machadinha era que minimamente colocassem alguém da própria comunidade para trabalhar dentro do Memorial. Isso foi concretizado no início de 2015: deslocou-se Dalma, neta de jongueiro para realizar as conduções turísticas dentro do Memorial e para reali- 
zar atividades com a própria população local. Durante a pesquisa, uma de suas conduções dentro do Memorial foi iniciada da seguinte forma:

Meu nome é Dalma, sou descendente de quilombola, moro aqui em Machadinha, moro em uma destas senzalas, a minha senzala fica na ala D; minha tataravó foi escrava, foi ama-de-leite do Visconde de Ururaí que morava na casa-grande que hoje está em ruínas ali [...] Nós somos da origem dos Kissama. Porque naquele tempo do Brasil Colônia, essas terras aqui não tinham nome e os 7 capitães vieram explorar aqui esta terra que não tinha nome e encontrou uma aldeia de indios, porque aqui foi dos indios Goitacazes... e o nome da aldeia era aldeia nova e encontrou um negro e esse negro [...]

Ao se apresentar para os turistas, Dalma inclui suas memórias pessoais partindo do recorte da memória da escravidão - uma memória genealógica na perspectiva da subalternidade e seu modo de pertencimento histórico ao local. Nota-se que o lugar identitário narrado presume uma concepção frigorificada de quilombo - a partir do passado colonial, e não do presente - mostrando a reconstituição da memória pelo viés do espaço social de onde ela fala. Ela utiliza a palavra "senzala" para designar a casa em que mora, apresentando um "lugar de memórias" que passa a ser objetificado. Como afirma o laudo antropológico do INCRA, existe tanto na exploração do mito do negro Kissama, quanto na utilização do termo "senzalas", um interesse em legitimar a origem negra para alimentar o investimento no turismo local evidenciando os efeitos das narrativas históricas no presente.

A forma de representação do passado durante o guiamento está relacionada, num primeiro momento, a uma memória canônica, enquadrada pelas necessidades do momento e pela sua função social no âmbito do trabalho. Dalma realiza recortes e enquadramentos da memória para o exercício da tarefa designada. Dentre estas reconstruções observa-se, no discurso da quilombola, uma introjeção - ou apropriação - do discurso de identidade imputado à população, a partir da narrativa do Poder Público - a origem de Machadinha diretamente ligada à Nação Kissama. Desta forma, observamos que a memória oficializada, emoldurada pela demanda da atividade turística, acaba por constituir um dos elementos importantes no atual processo de construção da memória coletiva e da identidade da população de Machadinha. A essencialização e homogeneização da origem identitária africana, enquanto elemento da memória coletiva, é parcialmente incorporada pela comunidade, que passa a ceder à força discursiva impressa no Memorial, constituído, desta forma, como um lugar "pedagógico". Não é possível deixar de observar, no entanto, que existe aqui uma fabricação de saberes por parte do poder local que se inicia a partir da reapropriação e reinvenção de um mito de origem contido nos relatos de um colonizador. $\mathrm{O}$ conhecimento, produzido e reproduzido numa forma de representação do passado dentro da estrutura do Memorial, revela um sutil controle social sobre a produção de memórias. Questiona-se, portanto: o que resta da perspectiva eurocêntrica neste modo de operacionalização da construção de um saber impresso na memória?

Ao abordarmos a noção de "colonialidade do saber", Quijano (2000) reflete sobre processos de produção de conhecimento e a colonialidade do poder interno, também operando em níveis locais. Como afirmam Restrepo e Rojas (2010), o que se denomina modernidade é o específico universo de relações intersubjetivas que se dá a partir da dominação eurocêntrica. Este modo de conhecimento forjado pela centralidade da Europa, que se autodenomina racional, surge como emblema da modernidade. Isso quer dizer que o eurocentrismo é, antes de tudo, uma perspectiva cognitiva que, no entanto, não é exclusiva dos europeus e nem do período colonial: ela transpassa o tempo também pertencendo aos que tenham sido educados pela sua hegemonia (QUIJANO, 2010). Ou seja, não apenas os europeus, mas seus descendentes diretos - e outros - passaram a reproduzir nos territórios coloniais uma perspectiva eurocêntrica do conhecimento (RESTREPO; ROJAS, 2010). Qual é o poder simbólico que a população de Machadinha possui neste processo de produção de saberes que acaba por impactar diretamente a construção de memórias, identidades e subjetividades locais? Acredita-se que a interioridade do imaginário social, submetido à colonialidade do poder em nível local pode ter impactos diretos sobre o processo de subjetivação. Aníbal Quijano (2000) propõe que na escala societal "o poder é um espaço e uma malha de relações sociais de exploração, dominação e conflitos que se articula em torno da disputa pelo controle de alguns âmbitos da existência social". Entre eles se encontra a "subjetividade e seus produtos materiais e intersubjetivos, incluindo o conhecimento" (QUIJANO, 2000, p. 345). As memórias de classe de determinados grupos sociais dominantes utilizam o poder simbólico e o poder político para fazer prevalecer sua representação de passado a partir de uma perspectiva eurocêntrica, evitando a polissemia de vozes e outros pontos de vista sobre a história. Isto ocorre de forma sutil, subliminar e sob novas roupagens "ético-políticas" que, paradoxalmente, se voltam para um contexto de valorização da cultura negra, reforçando, no entanto, a relação destas memórias inventadas ou reconstruídas com o poder instituído. É neste sentido que podemos pensar em abuso de memória: aquela que resulta de uma manipulação orquestrada da memória e do esquecimento por detentores do poder (RICOEUR, 2007). A busca por uma "origem" pura tal como foi realizada, reforçando um processo de construção identitária monocultural, nos conduz a um tempo pré-diaspórico transcendente, a-histórico, na fabricação ativa de uma memória essencializada que se baseia prioritariamente em um mito de origem: observa-se, na concepção do Memorial, uma visão absolutista e cristalizada de cultura e identidade.

Ao longo da visitação observa-se, porém, que Dalma passa também a incluir suas próprias memórias entrelaçadas à memória oficial e canônica da escravidão. Ao mostrar fotos de antigos escravos trabalhando, ela narra que uma determinada ilustração se parece com a imagem que 
ela tem do seu pai quando estava vivo pouco tempo atrás. A forma como Dalma, ao mesmo tempo, coaduna com a memória oficializada em torno de um mito fundacional de origem e, sutilmente, reconstrói as próprias contramemórias, faz deste "lugar de memória" um espaço de silencioso conflito. Neste espaço, a colonialidade do saber convive ao lado das sutis táticas de resistência que instauram novos saberes: saberes subalternos pela via da experiência testemunhal. Ao realizar uma livre transição entre a memória clássica da escravidão e as suas lembranças pessoais de vida, Dalma não deixa de subverter a lógica do espaço-tempo coreografado do Memorial: antes de tudo, ela mostra as brechas temporais entre o colonialismo e o neoliberalismo, denunciando a continuidade da racionalidade moderna capitalista-racista nas relações sociais através do tempo e dos diferentes sistemas políticos. Ao cumprir sua função social designada de guia, porém, ela não realiza esta narrativa polifônica de forma ingênua, e sim, ocupa discretamente o espaço político da memória. Estabelece-se, na sua narrativa, portanto, a porosidade temporal entre a memória da escravidão e a sua memória de vida pela via do testemunho narrado: uma das possibilidades de costura da memória coletiva. Deve ser destacado o caráter fortemente delineado do campo da experiência: ela testemunha a história transgeracionalmente, subvertendo a lógica da linearidade temporal - subversões só possíveis por meio da memória. Ao utilizar com veemência a importante categoria temporal da população, afirmando "eu alcancei [esta época]" - ela dá veracidade e legitimidade ao tempo experienciado, e sua memória se torna ação: a ação de transmissão de um conhecimento vivido - a dimensão política do testemunho narrado. Ela não aborda uma origem transcendental e essencializada africana, mas sim seu próprio berço de infância. Beatriz Sarlo (2007, p. 26) chama de experiência "o que pode ser posto em relato: algo vivido que não apenas se sofre, mas se transmite". Dalma, neste momento, fala como narradora e não como guia turística: ela se abre para as afetações do seu passado no processo de reconstituição de sua história de vida junto à memória clássica da escravidão e oferece sua narrativa aos ouvintes em forma de testemunho-saber.

Paralelamente aos intensos movimentos de transformação das práticas culturais e do espaço físico-social da comunidade junto ao projeto de construção do Complexo Cultural, observamos, portanto, por parte do poder local, um discurso político-identitário essencialista que valoriza e enaltece as raízes africanas numa palpável tendência pela idealização de um "retorno místico" - o Memorial Machadinha é o "lugar de memória" que materializa essa visão em torno de uma origem purista. Junto à demanda da atividade turística, ao ser construído e planejado pela prefeitura a partir de uma concepção superintegrada de cultura, o Memorial trouxe uma narrativa essencializada africana, construindo nuances puras, absolutistas e fixas à identidade local. Destaca-se mais uma vez que a narrativa intencional de verossimilhança física direta entre os dois povos, a população de Machadinha e a população de Angola, traz um tempo a-histórico, cuja reconstituição da origem africana, mesmo hipoteticamente, possibilita o esquecimento simbólico do rastro da escravidão e seus desdobramentos nas injustiças presentes. A memória da escravidão, a partir da narrativa de retorno às origens, é substituída por uma "noção mística da África, tornando-se indiferente à variação intrarracial", e, portanto, congelando a história "no ponto em que os negros embarcaram nos navios que os levariam para os inimigos e horrores da Middle Passage" (GILROY, 2003, p. 355).

\section{Conclusão}

$\mathrm{O}$ artigo busca inserir o pensamento pós-colonial na pesquisa em psicossociologia numa perspectiva que contemple abordagens teórico-metodológicas problematizadoras no âmbito das práticas sociais, possibilitando, assim, a tradução das narrativas de grupos sociais vulneráveis. A produção de conhecimento e saberes contra-hegemônicos de populações historicamente excluídas ocorre de forma subliminar a partir de sutis táticas de resistência no espaço público. Neste contexto, discute-se a dimensão conflituosa da memória junto ao processo de construção identitária e as dissonantes representações do passado encenadas no palco contemporâneo: a busca da legitimação - assim como os processos reiterados de negociação da memória - ocorre em torno das relações de poder entre a comunidade quilombola e a administração pública local. Neste palco observamos o aspecto multivocal da memória e a relação instrumental e ideológica com o passado. Essas vozes dissonantes - enquanto ecos do passado no presente que o reconstrói permanentemente a partir de demandas sociais por parte de diferentes grupos sociais - acabam por constituir ambivalentes processos de comunicação e pequenas brechas discursivo-temporais por onde as vozes marginalizadas surgem como "contramemórias" de uma narrativa oficial. Este processo de conflito de memórias, no entanto - mesmo que se evidencie um diferencial de poder - não ocorre de forma estanque e maniqueísta (memória oficial versus memória subalterna), mas sim a partir de silenciosas negociações e de múltiplas apropriações de alguns aspectos da narrativa oficial que passam a constituir parcialmente a construção identitária por parte da comunidade - memórias consonantes - e a construção das próprias narrativas e memórias que passam a ocupar, laboriosa e politicamente, o espaço público - memórias dissonantes.

A essencialização da identidade de Machadinha e a cristalização de sua origem a partir do discurso do poder local em torno do mito fundacional do município se inscrevem no exercício da colonialidade do saber, reforçada pelas práticas culturais no contexto do turismo. Este movimento desloca a historicidade da escravidão das articulações culturais e movimentos tradutórios que ocorreram no contexto colonial e da luta de classes. O discurso essencialista do poder local em torno da reconstrução do mito fundacional de origem do negro Kissama fixa a identidade de Machadinha a uma ancestralidade africana distante, impactando o processo de construção da memória coletiva. No entanto, a comunidade se apropria parcialmente deste ícone objetificado nas suas práticas poéticas e cotidianas, inserindo suas reivindica- 
ções diante da construção da identidade quilombola.O Memorial Machadinha se torna um espaço de conflitos e negociações de memórias entre o discurso canônico do poder local e a inscrição político-poética do testemunho que surge no espaço público como fonte de saber da comunidade, revelando as entrelinhas dos processos sociais mediados pelas relações de poder.

\section{Informações sobre a autora:}

Heliana Castro Alves

\section{(iD) https://orcid.org/0000-0001-8034-9648}

(9) http://lattes.cnpq.br/1048145085222187

Docente do curso de Terapia Ocupacional da Universidade Federal do Triângulo Mineiro. Doutorado em Psicossociologia de Comunidades e Ecologia Social pelo Programa EICOS/ UFRJ, realizou estágio doutoral na Université de Lille 3, França (programa Capes Cofecub). Pesquisadora do Núcleo de Estudos e Pesquisas em Vulnerabilidade e Saúde na Infância e Adolescência (NEPVIAS) e do Laboratório do Laboratório de Memórias, Territórios e Ocupações: rastros sensíveis, UFRJ. Possui experiência na Área Social a partir de ações territoriais, com ênfase em Arte, Cultura, Arte-Educação, Cidadania Cultural, Comunidades Tradicionais e direitos humanos, atuando principalmente nos seguintes temas: pós-colonialismo, identidade cultural, igualdade racial, vulnerabilidade social; memória social, violência e desenvolvimento humano/ comunitário.

\section{Como citar este artigo:}

\section{ABNT}

ALVES, Heliana Castro. Colonialidade do saber e conflitos de memórias no espaço público. Fractal: Revista de Psicologia Dossiê Psicologia e epistemologias contra-hegemônicas, Niterói, v. 31, n. esp., p. 195-200, set. 2019. https://doi.org/10.22409/19840292/v31i_esp/29050

\section{APA}

ALVES, H. C. (2019, set.). Colonialidade do saber e conflitos de memórias no espaço público. Fractal: Revista de Psicologia Dossiê Psicologia e epistemologias contra-hegemônicas, 31(esp.), 195-200. doi: https://doi.org/10.22409/1984-0292/v31i_esp/29050

\section{Referências}

FOUCAULT, Michel. A Arqueologia do saber. Rio de Janeiro: Forense Universitária, 2013.

GILROY, Paulo. O Atlântico Negro: modernidade e dupla consciência. Rio de Janeiro: Editora 34/UCAM - Centro de Estudos Afro-Asiáticos, 2003.

HALBWACHS, Maurice. A memória coletiva. São Paulo: Vértice, 2006.

MARIANI, Alayde Wanderley. Sociologia: Quissamã, história e sociedade. In: MARCHIORI, Emília Prado et al. Quissamã. Rio de Janeiro: SPHAN / Fundação Nacional Pró-Memória, 1987. p. 29-46.

MARTÍN-BARBERO, Jesús. Dos meios às mediações: comunicação, cultura e hegemonia. Rio de Janeiro: UFRJ, 1997.

QUIJANO, Anibal. Colonialidad y Modernidad-Racionalidad. In: BONILLA, Heraclio (Org.). Los conquistados: 1942 y la población indígena de las Américas. Quito: FLACSO, 1992. p. 437-449.
QUIJANO, Anibal. Colonialidad del poder, Eurocentrismo, America Latina. In: LANDER, Edgardo (Ed.). La colonialidad del saber: eurocentrismo y ciências sociales. Perspectivas latino-americanas. Caracas: Clacso, 2000. p. 201-245.

QUIJANO, Anibal. Colonialidade do poder e classificação social. In: SANTOS, Boaventura de Sousa; MENESES, Maria Paula. (Org.). Epistemologias do sul. Coimbra: Almedina, 2010. p. 73-116.

RESTREPO, Eduardo; ROJAS, Axel. Inflexión decolonial: fuentes, conceptos y cuestionamientos. Colômbia: Editorial Universidad del Cauca, 2010.

RICOEUR, Paul. A memória, a história, o esquecimento. Campinas: Unicamp, 2007.

SÁ, Celso Pereira de. Sobre o campo de estudo da memória social: uma perspectiva psicossocial. Psicologia: Reflexão e Crítica, Porto Alegre, v. 20, n. 2, p. 290-295, 2007. http:// dx.doi.org/10.1590/S0102-79722007000200015

SARLO, Beatriz. Tempo passado: cultura da memória e guinada subjetiva. Belo Horizonte: Cia das Letras/UFMG, 2007.

SILVA Leonardo de Vasconcelos. Machadinha: origem, história e influências. Rio de Janeiro: EDG, 2009. 